Roy, S. and Balaji, M. and Quazi, A. and Quaddus, M. 2018. Predictors of customer acceptance of and resistance to smart technologies in the retail sector. Journal of Retailing and Consumer Services. 42: pp. 147-160.

(c) 2018. This manuscript version is made available under the CC-BY-NC-ND 4.0 license http://creativecommons.org/ licenses/by-nc-nd/4.0/

\title{
PREDICTORS OF CUSTOMER ACCEPTANCE AND RESISTANCE OF SMART TECHNOLOGIES IN THE RETAIL SECTOR
}

Roy, S. and Balaji, M. and Quazi, A. and Quaddus, M.

\section{Abstract}

The rapid advancements in Internet technology have led to the development of numerous innovative smart technologies. This research investigates the customer acceptance and resistance of smart technologies in the retail sector by integrating the technology acceptance model, system characteristics, technology readiness, and store reputation literature. Data was collected using a quantitative survey and analysed using symmetrical PLS path modelling and asymmetrical fuzzy set qualitative comparative analysis (fsQCA). Results show complex relationships among perceived technology readiness, perceived ease of use, perceived usefulness, superior functionality, perceived adaptiveness, and store reputation in determining customers' attitude and behavioural intentions towards smart retail technologies. The findings also show that technology readiness does not directly affect customer attitude but indirectly through perceived innovation characteristics. The findings indicate that retail stores should focus on smart technologies that are simple, yet offer enhanced customer value by improving the shopping efficiency. Retail stores can engage in brand management strategies to improve customers' acceptance of SRT.

Keywords: Smart technology, Internet of things, technology acceptance model, technology readiness, PLS path modelling, fsQCA. 


\section{Introduction}

The rapid diffusion of Internet technology is dramatically transforming the retail industry and customer shopping experience. One notable application is the introduction of smart technology by many leading retailers all over the world (Inman \& Nikolova, 2017; Renko \& Druzijanic, 2014). The smart retail technology (hereafter, SRT) is an interactive retail system which delivers retail services to consumers through a network of smart or intelligent objects and devices. These connected devices can sense the surroundings and engage in real-time data collection, communication, interaction, and feedback (Wünderlich et al., 2015). SRTs can be integrated into the existing retail environment extending from product displays to shopping aisles and to even fully immersive retail stores. For example, Rebecca Minkoff recently introduced a 'connected wall' that consists of a mirrored display which allows consumers to virtually try-on the clothing, create outfits from the retailers' inventory, request matching items, order drinks, and even connect to the social media (Willems et al., 2017). Thus, SRT represents a major step forward in the use of information technology in the retail sector where the physical and digital dimensions are integrated to create a unique shopping experience tailored to the customer's needs. According to a recent report, investment in SRT is predicted to reach $\$ 36$ billion by 2020 (Research and Markets, 2015).

The implementation of SRT is expected to bring substantial benefits such as lower labour costs and increased efficiency for retailers and greater convenience, accessibility, and increased interaction for customers (Wünderlich, Wangenheim, \& Bitner, 2013; Roy et al., 2017). Due to widespread adoption and benefits of SRT, extant literature suggests more indepth research in this space. For example, Gao and Bai (2014) contend that there is a lack of research examining the customer adoption of smart technology. Garaus, Wolfsteiner, and Wagner (2016) suggest that influence of smart technology on customer behaviour in retail sector represents a fertile area for further investigation. More recently, Inman and Nikolova 
(2017) highlight the dearth of research related to the customer perception of smart technology in the retail industry. Ignoring these calls for research may result in a lack of understanding of customer decision to adopt SRT (Claudy, Garcia, \& O’Driscoll, 2015). Given the long adoption process and high costs of smart technology systems, there is a need for retailers to understand the drivers of customer adoption of SRT. Moreover, as all innovations face some form of consumer resistance (Laukkanen, 2016; Mani \& Chouk, 2017), retailers must overcome consumer resistance for successful adoption of SRT. Thus, the primary objective of this study is to examine the factors which promote as well as hinder SRT adoption. This study notably integrates the technology acceptance model (TAM: Davis, 1989), technology readiness perspective (Parasuraman, 2000), and organisational theory (Damanpour, 1991) to examine how consumers evaluate SRT on perceived usefulness, perceived ease of use, superior functionality, perceived adaptiveness, technology readiness, and store reputation in determining their attitude and behavioural intentions.

The contributions of the present study are threefold. First, this study examines the factors that drive customer adoption of and resistance to SRT. As traditional retail stores are facing huge challenges from online retailers (Chiu et al., 2011), SRT has been mooted as a promising tool to reduce the customer churn by offering a new and unique in-store experience (Kim et al., 2017). However, as SRT is still in the nascent stage, many retailers are apprehensive about its ability to add value to customers. Additionally, the introduction of SRT in retail stores can lead to high customer resistance. While the majority of prior studies have focused on adoption behaviour, little research has investigated customer resistance of technology innovations (Talke \& Heidenreich, 2014; Laukkanen, 2016). It hence seems relevant and timely to examine the factors that motivate and hinder SRT adoption.

Second, this study extends the traditional technology acceptance research by developing an integrated model based on TAM, technology readiness, and organisational theory 
perspectives. While TAM offers a promising theoretical background for investigating SRT, many researchers recommend expanding the theory by considering system characteristics, individual differences, facilitating conditions, consumer traits and organization characteristics as exogenous variables of TAM model (Venkatesh \& Bala, 2008; Kwee-Meier, Bützler, \& Schlick, 2016, Gelderman, Paul, \& Van Diemen, 2011; Rosenbaum \& Wong, 2015, Purohit \& Srivastava, 2001). In response to call for expanding TAM (Kaushik \& Rahman, 2015; Stern et al., 2008), this study examines the role of system characteristics (superior functionality, perceived adaptiveness), consumer trait (technology readiness) and organisation characteristic (store reputation), to add to the knowledge on SRT acceptance and resistance.

Third, previous research has been equivocal regarding the linkages between beliefs, attitude, and intentions (Bagozzi, 2007). Based on the recommendations of Carrión et al. (2016), this study uses a sequential approach of partial least squares structural equation modelling (PLS-SEM) and fuzzy-set qualitative comparative analysis (fsQCA) to tease out the complex relationships among the determinants of customers' acceptance and resistance (attitude and intentions) of SRT. Ordanini, Parasuraman, and Rubera (2014) suggest that the same innovation attributes can either foster or inhibit new service adoption depending on how they are configured with other attributes. Moreover, the multi-criteria decision-making literature (Bous et al., 2010, Scholz et al., 2017) suggest that consumers consider all attributes (conditions) at once in a holistic manner to arrive at a decision commensurate with their preferences. Thus, consumers may rely on various attributes in their decision to adopt or resist new technology. In doing so, they may emphasize (or neglect) a condition - thus creating a configuration to decide on the technology acceptance. A combinatorial approach using PLS-SEM and fsQCA can thus offer detailed insights into the factors driving SRT 
adoption and resistance (Liu et al., 2017). Consequently, this study uses PLS-SEM and fsQCA analyses to examine the determinants of customer acceptance and resistance to SRT.

The rest of the article is structured as follows. The next section presents the literature review and the research framework, followed by the research methodology. Finally, results are discussed with implications, novelties and limitations of the study as well as future research directions are presented in the last section.

\section{Literature Review and Research Hypotheses}

The research model, presented in Figure 1 proposes the role of technology beliefs of perceived usefulness and perceived ease of use, SRT-related system characteristics of superior functionality and perceived adaptiveness, consumer trait of technology readiness, and organisation characteristic of store reputation in customers' perceived acceptance (attitude and behavioral intentions) of SRT in retail setting. This integrated model is supported by the social cognitive theory (Bandura, 1986) which states that socioenvironmental, personal, and behavioral factors are key determinants of customers' behaviour.

[Insert Figure 1 about here]

\subsection{Technology Readiness}

Technology readiness is an "individual's propensity to embrace and use new technologies" (Parasuraman, 2000, p. 308). Technology readiness relates to the perceptions, beliefs, and feelings an individual hold with respect to high-tech products and services. Previous research suggests that an individual can at the same time, present both favourable and unfavourable technological beliefs and the balance between these beliefs determines their predisposition to accept or reject a new technology (Rosenbaum \& Wong, 2015). Consequently, individuals with a high positive view towards technology are more likely to be receptive towards a new technology, while those with a high negative view are likely to resist acceptance of new technological products and services. Technology readiness is a global measure of technology 
propensity that is both individual-specific and system-independent. Technology beliefs and perceptions are classified along four distinct dimensions which include: optimism, innovativeness, discomfort, and insecurity (Parasuraman, 2000).

Optimism is the positive feeling that new technology offers customers with increased control, efficiency, and flexibility. Innovativeness relates to the belief that acceptance of a new technology makes the customer become a technology pioneer or opinion leader. Discomfort relates to customers' perception of lack or control and understanding of new technology. Finally, insecurity refers to customers' distrust and scepticism about the ability of new technology to meet their goals (Parasuraman, 2000). While optimism and innovativeness are considered as enablers or technological beliefs that increase an individual's propensity to adopt a new technology, insecurity and discomfort act as inhibitors resisting acceptance of new technology. Thus, technology readiness describes a set of enablers and inhibitors that collectively shape the customers' favourable or unfavourable perceptions of beliefs towards SRT.

The relationship between technology readiness and technology beliefs of perceived usefulness and ease of use is intuitive. As customers with high levels of technology readiness are more likely to have a favourable view of the new technology, it is likely that they are capable of viewing the usefulness related to acceptance of SRT. In the same way, customers with high levels of technology readiness can cope with the challenges and discomfort associated with using new technology. Thus, customers with high technology readiness are likely to have greater ease of understanding the advanced features and functions of SRT and also as to how to use SRT in accomplishing their shopping goals and tasks. For example, Lin and Chang (2011) showed that technology readiness significantly affects customers' perceived ease of use, perceived usefulness, attitude, and behaviour towards self-service technology. Ferreira, Da Rocha, and Da Silva (2014) found that technology readiness has a 
direct impact on perceived ease of use, perceived usefulness, and relative advantage for high technology products in Latin America. Laukkanen, Sinkkonen, and Laukkanen (2008) propose that technology readiness acts as a psychological barrier for adoption of new technologies. Specifically, customers might feel frustrated with new technologies, and this inhibits them from accepting SRT. More recently, Boon-itt (2015) demonstrated that customers' technology readiness impacts their assessment of service quality dimensions and satisfaction with the self-service technology. Based on the above discussion and empirical evidence, we propose the following hypotheses:

$\mathbf{H}_{1 \mathbf{a}}$. Technology readiness positively affects customers' attitude towards SRT.

$\mathbf{H}_{\mathbf{1 b}}$. Technology readiness positively affects customers' perceived usefulness of SRT.

H1c. Technology readiness positively affects customers' perceived ease of use of SRT.

H1d. Technology readiness positively affects customers' superior functionality of SRT.

$\mathbf{H}_{1 \mathrm{e}}$. Technology readiness positively affects customers' perceived adaptiveness of SRT.

\subsection{Technology Acceptance Model}

The technology acceptance model (Davis, 1989) was developed based on the theory of reasoned action (Ajzen \& Fishbein, 1980) and the theory of planned behaviour (Ajzen, 1985). TAM has been used extensively in understanding and exploring the drivers of adoption of new technology by individuals and organisations (Legris, Ingham, \& Collerette, 2003; Reinders et al., 2015; Hernandez et al., 2009). It has also been used to determine the motivations or willingness of customers to adopt new technology. Likewise, TAM is useful to develop or predict the system-specific benefits that are critical for customers to maintain a long-term working relationship with a new technology. In the marketing and retail setting, TAM has been applied to a wide range of technology adoptions in different contexts such as Internet banking, mobile banking, mobile commerce, RFID, augment realty, electronic labels, 
adoption of e-health, e-financial services, and NFC (Gao \& Bai, 2014; Garaus et al., 2016). Thus, TAM serves as a useful foundation for examining customer acceptance of SRT.

TAM is a parsimonious and robust model which suggests that customers' acceptance of a new technology is significantly driven by two determinants namely perceived usefulness and perceived ease of use of the new technology (Davis, 1989). Perceived usefulness refers to the ability of the SRT to help customers perform and complete their shopping tasks more efficiently and effectively. On the other hand, perceived ease of use refers to the ease with which customers can use SRT in completing their shopping tasks. It is evident from the extant literature that perceived ease of use affects customers' behaviours directly and indirectly through perceived usefulness (Davis, 1989).

For example, Ha and Stoel (2009) used TAM to examine factors influencing customers' acceptance of e-shopping. The authors find that the critical beliefs about online shopping, i.e., perceived ease of use and perceived usefulness are key determinants of successful adoption of online shopping. Specifically, while perceived usefulness had a direct effect on attitude towards e-shopping, perceived ease of use had an indirect effect through perceived usefulness. Kim et al. (2017) and Mital et al. (2017) found that perceived usefulness, perceived ease of use, and perceived enjoyment are significant factors determining the adoption of smart retail technologies. Mani and Chouk (2017) demonstrated that innovation characteristics such as perceived uselessness and novelty result in customer resistance towards smart products. Further, Hilken et al., (2017) argue that one specific form of SRT (i.e., augmented reality) based service augmentation has positive impacts on customers' utilitarian and hedonic values, offering personalized services and more enjoyable and easy shopping experience. For consistency and comparison with other studies on new technology acceptance, the following hypotheses are presented for testing:

$\mathbf{H}_{2 \mathbf{a}}$. Perceived usefulness positively affects customers' attitude towards SRT. 
$\mathbf{H}_{2 \mathbf{b}}$. Perceived usefulness positively affects customers' behavioral intentions towards SRT.

$\mathbf{H}_{2 \mathbf{c}}$. Perceived ease of use positively affects customers' attitude towards SRT.

H2d. Perceived ease of use positively affects customers' attitude towards SRT through perceived usefulness.

$\mathbf{H}_{2 \mathbf{e}}$. Attitude positively affects customers' behavioral intentions towards SRT.

\subsection{Superior Functionality and Perceived Adaptiveness}

Superior functionality describes the extent to which SRT offer customers with relatively superior and advanced functions over the existing formats of retail technology. As mentioned earlier, SRT is a more advanced interactive and networked technology which is a self-aware, connected, and proactive system that offers a unique and seamlessly integrated shopping experience (Pantano \& Timmermans, 2014; Pantano et al., 2017; Wünderlich et al., 2015). The diffusion of innovation theory suggests that relative advantage of a new technology is related to the customers' belief that it offers greater benefits and value (Rogers, 2004). When retail consumers evaluate SRT as having superior features and functions, they are more likely to trust it and perceive it as offering high-quality retail services. This leads to a favourable evaluation of SRT. For example, Ferreira, Da Rocha, and Da Silva (2014) showed that relative advantage offered by electronic book readers affect customers' perceived usefulness and attitude towards its successful adoption. Similarly, Lu et al. (2015) found that relative advantage determines the behavioral intentions and actual usage of mobile banking services. More recently, Garaus et al. (2016) show that the relative advantage of electronic shelf labels in reducing the potential errors of wrong prices, compared to traditional price tags leads to a greater perception of its usefulness for shoppers. Thus, when consumers perceive SRT as offering superior functions and benefits, they are more likely to evaluate it as useful and develop a favourable attitude towards SRT. On the contrary, consumers might resist adopting 
SRT if they perceive the SRT does not provide superior benefits or performance to existent retail technologies. Based on the above discussion, we advance the following hypotheses:

$\mathbf{H}_{3 a}$. Superior functionality positively affects customers' attitude towards SRT.

$\mathbf{H}_{3 \mathbf{b}}$. Superior functionality positively affects customers' perceived usefulness of SRT.

The extent to which the SRT can be adaptive to changes in the environment, customers, and context is crucial for its successful acceptance (Pantano \& Timmermans, 2014). Perceived adaptiveness refers to the ability of SRT to offer a rich and personalized retail service as desired by customers. SRTs are equipped with sensing capabilities that present unprecedented opportunities for the retailer to understand retail shoppers' behavioral patterns and personal contexts. This provides flexibility for the retailer to adapt to the diverse needs of the customers by offering a more efficient shopping experience. In other words, as SRT allows retailers to meet customer needs more closely, it is expected to improve customers' perception of the usefulness of the technology. This results in a favourable attitude and acceptance of SRT. For example, Wang and Li (2012) found that personalisation positively influences intentions to adopt mobile services through the perception of service quality and loyalty. Similarly, Neuhofer, Buhalis, and Ladkin (2015) suggest that accumulation of knowledge about the customer needs is important for retailers to provide personalised interaction and services to customers through SRT. Moreover, the authors argue that adaptability allows customers to co-create personalised retail services and experiences. Thus, we propose the following hypotheses:

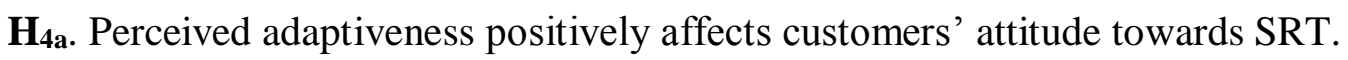

H4b. Perceived adaptiveness positively affects customers' perceived usefulness of SRT. 


\subsection{Store Reputation}

The present study considers the role of store reputation as an organisational characteristic facilitating our understanding of customer acceptance of SRT. Store reputation is defined as customers' overall evaluation of the retail store brand (Bao, Bao, \& Sheng, 2011). It represents the ability of the retail store to deliver valued outcome to customers and other stakeholders (Lee \& Shavitt, 2006). In general, organisational theory suggests that organisational characteristics can influence technology acceptance. Few studies specifically explore the role of organisational factors in new technology acceptance. In this study, we propose that retail stores with a high level of reputation will lead to a more favourable attitude and behaviour towards SRT. This is because store reputation represents global judgments about the retailer's qualities built over the past. For example, Wang and Li (2012) show that service providers' brand equity positively influences customer acceptance of mobile services. More recently, Beck and Kenning (2015) demonstrate that retail store image and trustworthiness enhances customers' perception of product trustworthiness and purchase intentions for new FMCG products. Boulding and Kirmani (1993) suggest that customers might use reputation as a cue to evaluate the high quality of technology offered. Thus, it is hypothesised that:

H5. Store reputation positively affects customers' attitude towards SRT.

\section{Research Methodology}

\subsection{Measures and Questionnaire}

The constructs in this study were measured using validated items from previous studies (See Appendix 1). A 12-item scale adapted from Rosenbaum and Wong (2015) was used to measure optimism, innovativeness, discomfort, and insecurity dimensions of technology readiness. A 4-item scale adapted from Venkatesh and Davis (2000) was used to measure 
perceived ease of use and perceived usefulness. The four-item scale for superior functionality was developed from Orel and Kara's (2014) and Wünderlich, Wangenheim, and Bitner's (2013) studies. The measurement items for perceived adaptiveness consisted of three items was adapted from Veloutsou and McAlonan (2012). Store reputation was measured using three items adapted from Bao, Bao, and Sheng (2011). Attitude towards SRT consisted of three 7-point semantic differential items adapted from Weijters et al. (2007). Finally, behavioral intentions towards SRT consisted of four items from Gao and Bai (2014). Responses to all questions (except for attitude towards SRT) were measured using a 7-point Likert scale ranging from "strongly disagree (1)" to "strongly agree (7)". The draft questionnaire was evaluated, and pilot tested with thirty students to check for ambiguous wording or expressions. After incorporating feedback received from pilot test into the questionnaire, the final questionnaire was then administered to actual retail shoppers in Australia.

\subsection{Sample and Data Collection Procedure}

The web-based survey data was collected in Australia. Over a three-week period in the first quarter of 2016, a marketing research company directed its consumer panel members to respond to the questionnaire on SRT in the retail context. An invitation to participate was issued with a small incentive and provided with a link to the survey questionnaire using Qualtrics. Upon consenting to participate, participants were requested to complete the questionnaire which contained measures of technology readiness, perceived ease of use, perceived usefulness, superior functionality, perceived adaptiveness, store reputation, attitude, and behavioral intentions along with items assessing behavioral and demographic characteristics. Clear instructions were provided in the questionnaire for potential respondents to respond based on their most recent experience with a SRT. We generated a common understanding of customer-facing SRT based on industry reports (Gregory, 2016) 
and existing literature (Priporas, Stylos, \& Fotiadis, 2017; Willems et al., 2017). The SRTs reported in the completed responses were smart checkouts, personal shopping assistance, point-of-sale smart displays, NFC systems, and augmented reality.

A total of 361 valid responses were obtained. Based on Soper (2014) sample size calculator, the total number of responses required for the model structure was found to be sufficient (the minimum sample recommended for structural equation modelling with 12 latent variables, 37 observed variables, p-level, 0.05, and anticipated size effect, 0.03 is 188). The t-tests did not reveal significant differences in the study constructs for the early and late response groups, suggesting that non-response bias is not a problem in this study. The respondents in the sample were distributed as follows: (1) 45 percent males and 55 percent females; (2) 56 percent of respondents belong to age group of 21 and 35 years; and (3) 54 percent had a bachelor's degree.

\subsection{Data Analysis}

The data analysis was carried out using sequential approach of partial least squares structural equation modelling (PLS-SEM) technique and fuzzy set qualitative comparative analysis (fsQCA). Vis (2012) suggests that a sequential approach that uses a traditional quantitative approach and a qualitative comparative analysis would be more useful for assessing the relationships as it allows us to learn more about the data. It allows the examination of the relationships between the exogenous and endogenous variables and facilitates the development of a comprehensive assessment of how a combination of various causal variables can produce a particular outcome (Ordanini, Parasuraman, \& Rubera, 2014; Carrión et al., 2016). For these reasons, this study uses the sequential approach of PLS-based analysis and fsQCA analysis to have a better understanding of SRT acceptance.

The PLS-SEM path modelling with SmartPLS 3.0 (Ringle, Wende, \& Becker, 2014) was used to assess the psychometric properties of the measurement variables and to test the 
research hypotheses. PLS-SEM was chosen as it works better at causal-predictive analysis when the hypothesized relationships are complex as is the present study. Besides, it allows testing of models that employ formative as well as reflective measures. PLS-SEM has minimal requirements concerning sample size, sample distribution, and measurement scales (Hair et al., 2012a). As recommended by Marcoulides, Chin, and Saunders (2009) and Hair et al. (2012b) measurement model is carried out before analyzing the structural model. The research model was tested using path-weighing scheme with a maximum of 300 iterations and 5000 bootstrap samples to compute t-statistics.

Along with PLS-based path modelling, fsQCA is used to complement the structural equation modelling. As PLS-SEM is a regression-based method in combination with factor analysis, issues related to regression analysis can also be applied to SEM (Liu et al., 2017). The fsQCA offers advantages such as equifinality, causal asymmetry, and makes associations based on theoretically meaningful thresholds (Rihoux \& Ragin, 2009). Also, fsQCA views outliers as highly significant to the phenomenon under study, unlike the regression analysis. In contrast to the regression analysis which tests the relationship between independent and dependent variables, fsQCA is a configurational approach exploring how causal conditions jointly as configurations can link to the outcome (Fiss, 2011). Thus, fsQCA considers the complex causal patterns among the independent variables and allows for in-depth insights into factors that determine the outcome.

\subsection{Common Method Bias}

Since the data was collected from a single source, common method bias could potentially impact the relationships between the constructs (Podsakoff et al., 2003). The common method bias was controlled using both procedural and statistical methods. In the study design, we allowed respondents to preserve their anonymity, emphasized that there are no right or wrong answers, requested to answer the survey questions as honestly as possible, used 
different scale formats (Likert scale and semantic differential scale), and refined item wording during pilot study (Podsakoff et al., 2003).

Concerning statistical remedies, Harman's single-factor test was performed, and it was found that no single factor exceeded the threshold of more than $50 \%$ of the total variance. Lindell and Whitney's (2001) marker variable technique was also employed. We used respondents' social networking sites use intensity, as an unrelated construct. Social networking sites use intensity which refers to the extent to which social networking sites are integrated into the daily routines of the respondents was measured with five items adopted from Valenzuela, Park, and Kee (2009). The inclusion of the marker variable did not significantly increase the variance of any dependent variable. Also, the average correlation between latent variables in the SEM and marker variable is 0.047 , and the average significance was 0.73 , which is well above the threshold of 0.05 which is necessary to consider the correlations as significant. Furthermore, the full collinearity approach showed that the value obtained for average full variance inflation factor (AFVIF) is 2.05, which is less than the threshold level of 3.3 (Kock, 2015). The use of procedural and statistical approaches (Harman's single factor, marker variable approach, and AFVIF) suggests that common method bias is not a major concern in this study.

\section{Results}

\subsection{Results concerning the measurement model}

As shown in Table 1, for the first-order variables, all item loadings are well-above the threshold level of 0.7 (except for two-items of technology readiness which were retained as it would impact the dimensionality of the construct and the constructs met the threshold levels of other validity and reliability criteria) (Anderson \& Gerbing, 1988). The reliability and convergent validity of the constructs are satisfactory as the composite reliability exceeded the 
recommended value of 0.70 and the average variance extracted exceeded the threshold value of 0.50 (Hair et al., 2012b).

[Insert Table 1 about here]

As confirmation of the existence of discriminant validity, the square root of AVE of each construct exceeded correlations between that construct and other constructs (Fornell \& Larcker, 1981). Table 2 presents the means, standard deviations, correlations, and the square root of AVE of the first-order constructs.

\section{[Insert Table 2 about here]}

The technology readiness was modelled as a second-order formative index with the four dimensions in combination providing an overall assessment of a consumer's beliefs to embrace new technology. This is consistent with Parasuraman (2000), who suggests that technology readiness combines the four dimensions which share weak correlations to provide a person's propensity to adopt new technologies. The degree of innovativeness and optimism are contributors of technology readiness while the degree of discomfort and insecurity acts as inhibitors of technology readiness.

Based on the recommendations of Hair et al. (2012a) and Peng and Lai (2012), we performed three statistical tests to address the reliability and validity of higher order technology readiness construct. First, as can be seen in Table 1, the coefficient of the four dimensions on the second-order construct was significant $(\mathrm{p}<0.01)$, indicating the nomological validity of the formative model. Further, it is desirable that the first-order dimensions do not share high correlations among them as this would challenge the discriminant validity of the four dimensions as formative indicators of technology readiness. As can be seen in Table 2, the four dimensions share weak correlations among them providing evidence of the discriminant validity of the formative model. Second, the variance inflation factor (VIF) for the four first-order dimensions was well below the cut-off threshold 
of 3.3 (optimism $=1.20$, innovativeness $=1.20$, discomfort $=1.80$. insecurity $=1.78$, indicating no multicollinearity among the formative dimensions. Finally, the results of the redundancy analysis (Christophersen \& Konradt, 2012) provide support for the convergent validity of the formative construct. These results support the second-order formative model of technology readiness.

\subsection{Results of the Structural Model}

Following the measurement model, the structural model was evaluated. Table 3 presents the path coefficients along with t-statistic.

[Insert Table 3 about here]

The $\mathrm{R}^{2}$ values for attitude towards SRT (0.46) and behavioral intentions towards SRT (0.36) exceed Falk and Miller (1992) criteria of $\mathrm{R}^{2}$ above 0.10 . The Stone-Geisser $\mathrm{Q}^{2}$ values for exogenous variables vary from 0.06 to 0.38 , indicating acceptable levels of predictive relevance (Chin \& Newsted, 1999). Further, the goodness-of-fit (GoF) defined "as the geometric mean of the average communality and the average $R^{2 \%}$ (Tenenhaus et al., 2005, p. 173) for the complete structural model was 0.49 , which shows that the model performs well.

As shown in Table 3, the structural model results show that majority of the hypotheses are supported. $\mathrm{H}_{1 \mathrm{a}-\mathrm{e}}$ predicted the role of technology readiness. $\mathrm{H}_{1 \mathrm{a}}$ and $\mathrm{H}_{1 \mathrm{~b}}$ were not supported since technology readiness did not show a significant impact on attitude $(\beta=-0.04, p=0.48)$ and perceived usefulness of SRT $(\beta=0.07, p=0.19)$. This was so even though literature states that consumers with higher technology readiness are more likely to perceive selfservice technologies as more useful and develop a positive attitude towards them. $\mathrm{H}_{1 \mathrm{c}-\mathrm{e}}$ are supported as perceived technology readiness positively influences perceived ease of use $(\beta=$ $0.37, \mathrm{p}<0.01)$, superior functionality $(\beta=0.26, \mathrm{p}<0.01)$, and perceived adaptiveness $(\beta=$ $0.16, \mathrm{p}<0.05)$ 
With reference to $\mathrm{H}_{2 \mathrm{a}-\mathrm{e}}$, the results confirm the relationship among the technology acceptance variables. Perceived usefulness positively influences attitude $(\beta=0.34, p<0.01)$ and behavioral intentions $(\beta=0.30, \mathrm{p}<0.01)$. Perceived ease of use positively influences attitude $(\beta=0.21, \mathrm{p}<0.01)$ and perceived usefulness $(\beta=0.52, \mathrm{p}<0.01)$. Finally, attitude has a positive influence on behavioral intentions towards SRT $(\beta=0.27, \mathrm{p}<0.01)$.

Regarding the influence of superior functionality $\left(\mathrm{H}_{3 \mathrm{a}}\right)$, we did not find support for its influence on attitude $(\beta=0.02, p=0.81)$. However, customer perception of superior functionality of SRT positively influences the perception of the usefulness of SRT ( $\beta=0.19$, $\mathrm{p}<0.05)$ and this supports $\mathrm{H}_{3 \mathrm{~b}}$. The post-hoc analysis reveals that perceived usefulness fully mediates the effect of superior functionality on attitude towards SRT. Perceived adaptiveness positively influences attitude $(\beta=0.15, \mathrm{p}<0.01)$ and perceived usefulness of SRT $(\beta=0.16$, $\mathrm{p}<0.01$ ), supporting $\mathrm{H}_{4 \mathrm{a}-\mathrm{b}}$. Concerning the role of organisational characteristics, store reputation positively influences customers' attitude towards SRT $(\beta=0.12, \mathrm{p}<0.05)$, supporting $\mathrm{H}_{5}$.

\subsection{Latent class analysis and multigroup analysis}

As recommended by Hair et al. (2012b), an exploratory latent class analysis using finite mixture modeling (FIMIX PLS) was carried out to test the rigor of our results, i.e., whether the results are homogenous across the samples. In determining the number of clusters, AIC and BIC should be minimized while EN should be maximized (Sarstedt \& Ringle, 2010; Hair et al., 2012b). Appendix 2 presents the fit indices for two and three cluster solutions. Concerning the number of clusters the findings are ambiguous while entropy and AIC support three cluster solution, BIC and CAIC supports two cluster solutions. However, a closer examination of the cluster solutions seems to indicate two dominant clusters in line with Sarstedt and Ringle's (2010) recommendations. This suggests that our sample is characterized by two clusters consisting of 196 and 65 respondents respectively. 
Multigroup analysis of the two groups using SmartPLS 3.0 shows that cluster one shows higher positive effect of technology readiness on attitude $(\beta=0.23, p<0.01)$, perceived ease of use $(\beta=0.55, \mathrm{p}<0.01)$, superior functionality $(\beta=0.56, \mathrm{p}<0.01)$, and adaptiveness $(\beta=$ $0.36, \mathrm{p}<0.01)$ while those in cluster two show negative effect on superior functionality $(\beta=-$ $0.34, \mathrm{p}<0.05)$ and adaptiveness $(\beta=-0.33, \mathrm{p}<0.01)$. Perceived usefulness was found to have a strong positive effect on behavioral intentions $(\beta=0.48, \mathrm{p}<0.01)$ in cluster two while it was not significant in cluster one $(\beta=0.15, \mathrm{p}=0.76)$. With regard to perceived ease of use, cluster one shows a stronger positive influence on perceived usefulness $(\beta=0.74, \mathrm{p}<0.01)$ while for cluster two, it is not significant $(\beta=0.05, \mathrm{p}=0.57)$. Finally, superior functionality was found to have a strong positive impact on perceived usefulness $(\beta=0.78, \mathrm{p}<0.01)$ for cluster one and it is not significant for cluster two $(\beta=-0.09, \mathrm{p}=0.08)$. Despite the differences in the path coefficients, no significant difference was observed in $\mathrm{R}^{2}$ for attitude and behavioral intentions towards SRT.

Post-hoc analysis reveals that cluster one shows significantly higher technology readiness $\left(\mathrm{M}_{1}=4.64, \mathrm{M}_{2}=4.25, \mathrm{p}<0.01\right)$, perceived ease of use $\left(\mathrm{M}_{1}=5.34, \mathrm{M}_{2}=4.93, \mathrm{p}<0.01\right)$, perceived adaptiveness $\left(\mathrm{M}_{1}=5.00, \mathrm{M}_{2}=4.64, \mathrm{p}<0.01\right)$, attitude $\left(\mathrm{M}_{1}=5.40, \mathrm{M}_{2}=5.08, \mathrm{p}<\right.$ $0.05)$, and behavioral intentions $\left(\mathrm{M}_{1}=5.36, \mathrm{M}_{2}=5.01, \mathrm{p}<0.05\right)$ towards SRT than cluster two. Chi-square test was carried out, and the results showed that these two clusters did not differ regarding demographics (age, gender, and education levels) and behavioral (SRT type). However, for SRT use significant difference exists between the two clusters with cluster one reporting greater use of SRT in their shopping trips in the last six months compared to cluster two. Results suggest that SRT acceptance differs across these two clusters. The results of cluster one point to the respondents who show greater propensity to embrace and use new technology and this facilitate their attitude and use of SRT. The results for cluster two indicate that while they evaluate SRT as offering superior functionality and its usefulness for 
shopping, their lack of readiness towards new technology hinders them from successfully accepting smart technology for retail shopping.

\section{4. fsQCA analysis}

As mentioned earlier this study also uses fsQCA to complement and supplement the results of SEM based analysis. fsQCA combines the determinants of SRT adoption and develops alternative necessary and sufficient configurations. However, we also analyze the antecedents and develop configurations for non-acceptance or resistance of SRT which will make a unique contribution to the extant literature. This study uses the fsQCA 2.5 software (www.fsqca.com) to analyze the data. We conduct two different analyzes. The first analysis explores the conditions that lead to the outcome of customers' attitude towards SRT and the second analyzes the conditions leading to behavioral intentions towards SRT. Three fundamental steps of fsQCA are fuzzy set calibration, development of truth table and analysis of the truth table solutions. These steps are described below.

The fuzzy set calibration process transforms a ratio or interval scale into a fuzzy set with membership scores between 0.0 and 1.0. To decide on the degree of membership in a fuzzy set we follow the procedure of Ragin (2008) and use three qualitative anchors as follows: threshold for full membership (fuzzy score $=0.95$ ), threshold for full non-membership (fuzzy score $=0.05$ ), and the cross-over point (fuzzy score $=0.05$ ). Since this study uses a 7 -point Likert scale, we reviewed the relevant extant literature to determine the corresponding values of Likert scale to convert into the fuzzy set. Ordanini et al. (2014) used the values of 6.0, 2.0 and 4.0 in their study. Following this, we used the anchor values of 6.0 (agree), 4.0 (neither agree nor disagree) and 2.0 (disagree) as full membership, cross-over point, and full nonmembership respectively (Ordanini et al., 2014).

The next step in fsQCA is the development of truth table which shows $2^{\mathrm{k}}$ possible combinations of conditions and the number of cases with fuzzy set membership score of 
greater than 0.5 (Ragin, 2008), where $\mathrm{k}$ is the number of conditions. It is noted that each row of the truth table is a possible configuration (recipe) and represents a point in a multidimensional fuzzy-set vector space (Ragin, 2008). The primary goal of the truth table is "to explicitly identify the connections between combinations of causal conditions and outcome" (Ragin, 2008, p. 38) and hence a truth table is a vital tool of fsQCA based analysis. To simplify the truth table, the frequency threshold and consistency threshold were set as par the guidelines of Ragin (2008). Four truth tables were developed as follows: (i) outcome variable 'attitude towards SRT (ATT)", (ii) outcome variable "negation of attitude towards SRT ( ATT), (iii) outcome variable 'behavioral intentions towards SRT (BIN)', and (iv) outcome variable 'negation of behavioral intentions towards SRT ( BIN)'.

The next step consists of the analysis of the necessary condition for testing if any of the causal conditions can be considered as necessary for the presence or absence of the outcomes (attitude and behavioral intentions). A condition is considered as "always almost necessary" if the consistency score exceeds the threshold level of 0.80 (Ragin, 2008). However, none of the variables was found to be a necessary condition for the customers' attitude and behavioral intentions towards SRT.

Following the necessity analysis, the analysis of sufficient conditions was carried out to detect the different causal configurations that lead to the attitude and behavioral intentions towards SRT. Table 4 summarizes the results of sufficiency analysis (frequency threshold of 2 ensuring that at least $80 \%$ of the cases are present in the analysis and consistency threshold of 0.97). As shown in Table 4, perceived usefulness (PUS), superior functionality (SFU), and perceived adaptiveness (ADP) are the core causal conditions for attitude towards SRT as they are part of the intermediate solution (Ragin, 2008). Solution 1 presents the recipe of conditions as PUS.PEO.SFU.ADP.REP, i.e., SRT with perceived usefulness, ease of use, superior functionality, perceived adaptiveness, and store reputation has a consistency index of 
0.97, raw coverage 0.72 and unique coverage of 0.08 . It is also observed that all three solutions in Table 4 have high consistency and coverage, indicating that these solutions substantially explain high attitude towards SRT. Finally, it is observed that along with the core condition of perceived usefulness, the noncore conditions of perceived ease of use and store reputation appear in all solutions in Table 4.

[Insert Table 4 about here]

Appendix 3 presents the configuration based on the core causal conditions of PUS.SFU.ADP for high attitude towards SRT (consistency index $=0.956$ and coverage $=$ 0.758). However, we also developed a configuration of PUS.PEO.REP combining the conditions which are present in all three solutions of Table 4. As shown in Appendix 4, this configuration has a consistency of 0.957 and coverage of 0.815 , and hence we conclude that this is the most significant configuration explaining the positive attitude towards SRT. The comparison of fsQCA results with that of PLS-SEM reveals that all three causal conditions of PUS, PEO, and REP individually impacts attitude towards SRT (see Table 3). However, the fsQCA results go beyond this in identifying the configurations of causal conditions which will impact attitude towards SRT substantially (PUS.PEO.REP). From a strategic planning point of view, knowledge of this configuration presents a host of possibilities to enhance the positive attitude towards SRT.

As can be seen from Table 4, the fsQCA truth table solution for the absence of attitude towards SRT ( ATT) reveals four solutions with consistencies greater than 0.75 , which is the minimum threshold of substantial consistency of any configuration (Ragin, 2008). However, as the minimum threshold value for raw coverage should be 0.50 (Ragin, 2008), only solution $1 \quad(\sim P U S . \sim S F U . \sim A D P . R E P)$ and $2 \quad(\sim P U S . P E O . \sim S F U . \sim A D P)$ are considered as configurations explaining the absence of attitude towards SRT. Table 4 also shows that absence of PUS and SFU are core causal conditions and appear in all solutions. The absence 
of ADP, a contributing causal condition, appears in three of the four solutions. We, therefore, developed a configuration of $\sim P U S . \sim S F U . \sim A D P$ to explain the absence of attitude towards SRT. This configuration has a consistency of 0.821 and coverage of 0.514 . Comparing with the configurations based on the core causal conditions, we conclude that the configuration $\sim P U S . \sim S F U . \sim A D P$ most substantially explains the absence of attitude towards SRT in terms of both consistency and coverage.

It has been shown earlier that perceived usefulness combined with perceived ease of use and store reputation (PUS.PEO.REP) is the most substantial configuration for a positive attitude towards SRT. However, for the absence of attitude towards SRT, the most substantial configuration is the negation of perceived usefulness combined with the negations of superior functionality and perceived adaptiveness ( $\sim P U S . \sim S F U . \sim A D P)$. This once again supports the causal asymmetry proposition that configurations fostering an outcome are not mirror opposites of configurations inhibiting the outcome (Wu et al., 2014). This is an interesting finding which shows what needs to be done to enhance the attitude and mitigate the absence or low levels of attitudes towards SRT.

Table 5 presents the results from fsQCA truth table solutions for behavioral intentions towards SRT (BIN). While four intermediate solutions are found, it is observed that only core condition of presence of BIN was the attitude towards SRT (ATT). While consistencies of the solutions are quite high, in terms of coverage solutions 2, 3, and 4 are notable. Each of these solutions has a combination of six causal conditions. It is noted that ATT and REP are common to all the solutions. Thus, a configuration of ATT.REP was developed for behavioral intentions towards SRT. Appendix 5 shows that the ATT.REP configuration has a perfect consistency of 1.0 and a high coverage of 0.893 . Thus, we conclude that ATT.REP is the most substantial configuration to explain BIN. This result supports the earlier result from PLS- 
SEM (see Table 3) where ATT was found to impact BIN significantly. However, via fsQCA, we found a recipe of ATT.REP to substantially impact BIN.

[Insert Table 5 about here]

As shown in Table 5, the results of the absence of behavioral intentions towards SRT $(\sim \mathrm{BIN})$ reveals that only solution $2(\sim S F U . \sim R E P)$ and $5(\sim P T R . \sim S F U . \sim A D P)$ are acceptable as consistency and raw coverage is greater than the threshold values of 0.75 and 0.50 respectively (Ragin, 2008). Since solution 5 is also a parsimonious solution (via truth table analysis), we conclude that this is the most substantial configuration for the absence of behavioral intentions towards SRT. Comparing with the substantial configuration (ATT.REP) for the presence of BIN it is noted that configuration $(\sim P T R . \sim S F U . \sim A D P)$ for the absence of BIN towards SRT is completely different.

\section{Discussion}

The findings of this study present several key insights associated with the proposed integrative framework of SRT. Using PLS-SEM and fsQCA, this research focuses on examining the main effects and the configurational combination of factors that influence consumers' acceptance and resistance to SRT. More specifically, this study shows how technology readiness, perceived ease of use, perceived usefulness, superior functionality, adaptiveness, and store reputation influence consumer attitude and behavioral intentions towards SRT.

\subsection{Theoretical Implications}

This study advances earlier research on technology acceptance by developing an integrative framework of SRT adoption. The PLS-SEM and fsQCA results confirm the role of various causal conditions and their combinations in determining the customer acceptance and resistance of SRT. Previous studies using TAM model have examined the role of perceived ease of use, perceived usefulness, perceived informativeness, interactivity, and 
novelty in technology acceptance (Gao \& Bai, 2014; Garaus et al., 2016; Hilken et al., 2017). As smart technology allows retail customer to personalize their interactions which leads to superior shopping performance (Inman \& Nikolova, 2017; Pantano et al., 2017; Wünderlich et al., 2015), the present study integrated superior functionality, perceived adaptiveness, and TAM model variables in understanding the customer acceptance and resistance of SRT.

The PLS-SEM and fsQCA results present some interesting findings. Regarding the role of technology readiness, the PLS-SEM results reveal that it does not influence consumer attitude towards SRT. This corroborates with the previous observation by Gelderman, Paul, and Van Diemen (2011) in the context of retail self-service technology acceptance. However, the latent class analysis offers insights on the role technology readiness plays in customer acceptance of SRT. We find that for segment one technology readiness has a greater impact on attitude, perceived ease of use, adaptiveness, and superior functionality. On the contrary, for segment two, technology readiness has a positive impact on perceived usefulness and negative impact on superior functionality and adaptiveness. The latent class analysis finding is consistent with Parasuraman and Colby (2015) who found technology readiness to impact new technology based on customers' beliefs and feelings. Furthermore, the results of fsQCA analysis reveal that the absence of technology readiness along with the absence of system characteristics of superior functionality and adaptiveness results in non-acceptance or resistance to SRT. Collectively, these findings suggest that under certain conditions and for certain customers, technology readiness influences customer acceptance towards SRT. Nevertheless, future research should explore the conditions under which technology readiness influences the customers' acceptance of new technology.

With regards to innovation characteristics, the PLS-SEM findings support the role of perceived usefulness, perceived ease of use, and perceived adaptiveness in determining customer acceptance of SRT. Furthermore, the fsQCA results reveal that these innovation 
characteristics within proper configurations lead to favorable attitude and behavioral intentions. These findings corroborate previous research findings on customer acceptance of retail technologies (Gao \& Bai, 2014; Kim et al., 2017). However, we observed conditional support for superior functionality as the configurations containing absence of superior functionality along with other innovation characteristics and individual trait factors result in the absence of attitude $(\sim P U S . \sim S F U . \sim A D P)$ and behavioral intentions $(\sim P T R . \sim S F U . \sim A D P)$ towards SRT. This extends our knowledge concerning the role of system characteristics in innovation adoption.

Based on the organisational theory, this study examined the role of store reputation in customer adoption of SRT. While prior literature has consistently reported the role of organization size, organizational strategy, and product category, this study considered retail store's reputation in SRT acceptance and resistance. The results support the organisational theory and demonstrate that overall evaluation of the retail store plays a key role in the development of favorable customer attitude towards SRT. Specifically, store reputation individually and in combination with perceived usefulness, perceived ease of use, and attitude drive customer acceptance of SRT. This finding is in line with previous studies highlighting the role of organisational characteristics in customer adoption of new product innovations (Wang \& Li, 2012).

Finally, the study findings provide insights into customer resistance of SRT. The fsQCA results show individual factors do not play a significant role in the absence of attitude towards SRT. However, configurations of negations of superior functionality, perceived usefulness, perceived adaptiveness and presence of store image result in consumer resistance towards SRT. This suggests that consumers might show resistance to SRT from high reputation stores that do not offer superior functions or benefits. This offers managers insights for improving the adoption process by uncovering what makes or does not make SRT 
attractive. Similarly, negations of superior functionality, perceived adaptiveness, and technology readiness results in the absence of behavioral intentions. Thus, to reduce SRT resistance, managers should customize the promotion strategy of SRT for different segments of customers based on technology readiness. These findings extend our understanding of factors that hinder customer adoption of SRT.

\subsection{Managerial Implications}

From a managerial perspective, the findings of the study have many implications for retail store managers and operators. First, the TAM variables perceived ease of use and perceived usefulness have a necessary and positive influence on customers' attitude, which in turn influences behavioral intentions. Therefore, retail stores should pay attention to adopt smart technologies that are user-friendly and ease-of-use. Smart technologies that are simple and possess practical features can reduce customer frustration and discomfort as well as improve their functionality to efficiently meet the customer needs. The study findings show that customer attitude seems to emerge in the presence of high superior functionality, high perceived ease of use, and high perceived usefulness. Therefore, retail stores should focus on smart technologies that are simple, yet offer enhanced customer value by improving the shopping efficiency. Development of such smart technologies requires an increased focus on customer testing and aligning the performance of SRT with customer expectations.

The findings show that technology readiness does not directly affect customer attitude but indirectly through perceived innovation characteristics. Furthermore, latent class analysis results confirm that customers with high levels of technology readiness are more likely to show the greater ease of use. Likewise, they see greater functionality and utility of SRT in shopping. Thus, retail stores should focus on customers' technology readiness and customize the smart technologies on the basis of varying levels of customers' technology readiness. Retail stores should provide necessary support to reduce discomfort and insecurity and 
strengthen the optimism towards SRT acceptance. The findings related to store reputation shows that customers view highly reputed stores as more trustworthy, and thus show favorable attitude and intentions towards SRT. This finding suggests that retail stores can engage in brand management strategies to improve customers' acceptance of SRT.

\subsection{Limitations and future research directions}

Despite its several important contributions to literature, the study is not free from limitations. First, this study focused solely on cognitive aspects of technology acceptance. As emotions also play an important role in consumption decisions of technological products, future research studies can, therefore, examine the cognitive and emotional aspects of SRT acceptance. Second, as successful implementation on SRT depends on continued use, this study collected responses from retail customers who had prior experience with SRT. Since the factors determining customer adoption and continuing use of technology products vary (Evanschitzky et al., 2015), future studies could examine the differential role of these factors in customers' initial trial and continued use of SRT. Third, this study offers conditional support for technology readiness in the outcome. Future research should assess the process of how technology readiness impacts customers' acceptance of SRT. Fourth, this study is undertaken in a developed country where consumer adoption of retail technologies is prevalent. Future research can be extended to developing countries such as Malaysia, India, and China towards enhancing the generalization of our integrated research framework. Fifth, this study examined behavioral intentions towards SRT. Future research could use field experiments and secondary data to examine to what extent TAM, technology readiness, and organisational characteristics influence actual behaviours in SRT. Finally, this study assessed customers' acceptance of SRT in general. As smart technologies vary in terms of their interactivity, presence, and risk perceptions (Wünderlich et al., 2015), future research can explore customers' acceptance of specific SRTs such as smart displays, smart shopping carts, 
or NFC-based systems and examine other customer behaviours in terms of increased usage of SRT or intentions to use other smart technologies.

\section{References}

Anderson, J. C., \& Gerbing, D. W. (1988). Structural equation modelling in practice: A review and recommended two-step approach. Psychological Bulletin, 103(3), 411-423.

Ajzen, I. (1985). From intention to actions: a theory of planned behaviour. In J. Kuhl, and J. Beckmann (Eds.). Action-control: From cognition to behaviour (pp. 11e39). Heidelberg: Springer

Ajzen, I., \& Fishbein, M. (1980). Understanding and predicting social behaviour, Englewood Cliffs, NJ: Prentice Hall

Bagozzi, R. P. (2007). The Legacy of the Technology Acceptance Model and a Proposal for a Paradigm Shift. Journal of the Association for Information Systems, 8(4), 244-254.

Bandura, A. (1986). Social foundations of thought and action: A social cognitive theory. Prentice-Hall, Inc.

Bao, Y., Bao, Y., \& Sheng, S. (2011). Motivating purchase of private brands: Effects of store image, product signatureness, and quality variation. Journal of Business Research, 64(2), 220-226.

Beck, S., \& Kenning, P. (2015). The influence of retailers' family firm image on new product acceptance: An empirical investigation in the German FMCG market. International Journal of Retail and Distribution Management, 43(12), 1126-1143.

Boon-itt, S. (2015). Managing self-service technology service quality to enhance esatisfaction. International Journal of Quality and Service Sciences, 7(4), 373-391.

Boulding, W., \& Kirmani, A. (1993). A consumer-side experimental examination of signaling theory: do consumers perceive warranties as signals of quality? Journal of Consumer Research, 20(1),111-123.

Bous, G., Fortemps, P., Glineur, F. \& Pirlot, M., (2010). ACUTA: A novel method for eliciting additive value functions on the basis of holistic preference statements. European Journal of Operational Research, 206(2), pp.435-444.

Carrión, G. C., Henseler, J., Ringle, C. M., \& Roldán, J. L. (2016). Prediction-oriented modelling in business research by means of PLS path modelling: introduction to a JBR special section. Journal of Business Research, 69(10), 4545-4551.

Chin, W. W., \& Newsted, P. R. (1999). Structural equation modelling analysis with small samples using partial least squares. Statistical Strategies for Small Sample Research, 2, 307342. 
Chiu, H. C., Hsieh, Y. C., Roan, J., Tseng, K. J., \& Hsieh, J. K. (2011). The challenge for multichannel services: Cross-channel free-riding behaviour. Electronic Commerce Research and Applications, 10(2), 268-277.

Christophersen, T. \& Konradt, U. (2012). Development and validation of a formative and a reflective measure for the assessment of online store usability. Behaviour and Information Technology, 31(9), 839-857.

Claudy, M. C., Garcia, R., \& O’Driscoll, A. (2015). Consumer resistance to innovation-a behavioral reasoning perspective. Journal of the Academy of Marketing Science, 43(4), 528544.

Damanpour, F. (1991). Organisational innovation: A meta-analysis of effects of determinants and moderators. Academy of Management Journal, 34(3), 555-590.

Davis, F. D. (1989). Perceived usefulness, perceived ease of use, and user acceptance of information technology. MIS Quarterly, 13(3), 319-340.

Evanschitzky, H., Iyer, G. R., Pillai, K. G., Kenning, P., \& Schütte, R. (2015). Consumer trial, continuous use, and economic benefits of a retail service innovation: the case of the personal shopping assistant. Journal of Product Innovation Management, 32(3), 459-475.

Falk, R. F., \& Miller, N. B. (1992). A primer for soft modelling, University of Akron Press.

Ferreira, J. B., da Rocha, A., \& da Silva, J. F. (2014). Impacts of technology readiness on emotions and cognition in Brazil. Journal of Business Research, 67(5), 865-873.

Fiss, P. C. (2011). Building better causal theories: A fuzzy set approach to typologies in organisation research. Academy of Management Journal, 54(2), 393-420.

Fornell, C., \& Larcker, D. F. (1981). Structural equation models with unobservable variables and measurement error: Algebra and statistics. Journal of Marketing Research, $18(3), 382-388$.

Gao, L., \& Bai, X. (2014). A unified perspective on the factors influencing consumer acceptance of internet of things technology. Asia Pacific Journal of Marketing and Logistics, 26(2), 211-231.

Garaus, M., Wolfsteiner, E., \& Wagner, U. (2016). Shoppers' acceptance and perceptions of electronic shelf labels. Journal of Business Research, 69(9), 3687-3692.

Gelderman, C. J., Paul, W. T., \& Van Diemen, R. (2011). Choosing self-service technologies or interpersonal services-The impact of situational factors and technologyrelated attitudes. Journal of Retailing and Consumer Services, 18(5), 414-421.

Gregory, J. (2016). The internet of things: Revolutionizing the retail industry. Accenture Strategy. Retrieved from https://www.accenture.com/gb-en/insight-internet-thingsrevolutionizing-retail-industry 
Ha, S., and Stoel, L. (2009). Consumer e-shopping acceptance: Antecedents in a technology acceptance model. Journal of Business Research, 62(5), 565-571.

Hair, J. F., Sarstedt, M., Pieper, T. M., and Ringle, C. M. (2012a). The use of partial least squares structural equation modelling in strategic management research: a review of past practices and recommendations for future applications. Long Range Planning, 45(5), 320-340.

Hair, J.F., Jr., Sarstedt, M., Ringle, C.M., \& Mena, J.A. (2012b). An assessment of the use of partial least squares structural equation modelling in marketing research. Journal of the Academy of Marketing Science, 40(3), 414-433.

Hernandez, B., Jimenez, J., and Jose Martin, M. (2009). Adoption vs acceptance of ecommerce: two different decisions. European Journal of Marketing, 43(9/10), 1232-1245.

Hilken, T., de Ruyter, K., Chylinski, M., Mahr, D., and Keeling, D. I. (2017). Augmenting the eye of the beholder: exploring the strategic potential of augmented reality to enhance online service experiences. Journal of the Academy of Marketing Science, 45(6), 884-905.

Inman, J. J., \& Nikolova, H. (2017). Shopper-Facing Retail Technology: A Retailer Adoption Decision Framework Incorporating Shopper Attitudes and Privacy Concerns. Journal of Retailing, 93(1), 7-28.

Kaushik, A. K., \& Rahman, Z. (2015). An alternative model of self-service retail technology adoption. Journal of Services Marketing, 29(5), 406-420.

Kim, H. Y., Lee, J. Y., Mun, J. M., \& Johnson, K. K. (2017). Consumer adoption of smart in-store technology: assessing the predictive value of attitude versus beliefs in the technology acceptance model. International Journal of Fashion Design, Technology and Education, 10, 26-36.

Kock, N. (2015). Common method bias in PLS-SEM: A full collinearity assessment approach. International Journal of e-Collaboration, 11(4), 1-10.

Kwee-Meier, Sonja Th, Jennifer E. Bützler, \& Christopher Schlick (2016). Development and validation of a technology acceptance model for safety-enhancing, wearable locating systems. Behaviour \& Information Technology, 35(5), 394-409.

Laukkanen, T. (2016). Consumer adoption versus rejection decisions in seemingly similar service innovations: The case of the Internet and mobile banking. Journal of Business Research, 69(7), 2432-2439.

Laukkanen, P., Sinkkonen, S., \& Laukkanen, T. (2008). Consumer resistance to internet banking: postponers, opponents and rejectors. International Journal of Bank Marketing, 26(6), 440-455.

Lee, K., \& Shavitt, S. (2006). The use of cues depends on goals: Store reputation affects product judgments when social identity goals are salient. Journal of Consumer Psychology, 16(3), 260-271. 
Legris, P., Ingham, J., \& Collerette, P. (2003). Why do people use information technology? A critical review of the technology acceptance model. Information and Management, 40(3), 191-204.

Lin, J. S. C., \& Chang, H. C. (2011). The role of technology readiness in self-service technology acceptance. Managing Service Quality: An International Journal, 21(4), 424-444.

Lindell, M. K., \& Whitney, D. J. (2001). Accounting for common method variance in cross-sectional research designs. Journal of Applied Psychology, 86(1), 114-121.

Liu, Y., Mezei, J., Kostakos, V., \& Li, H. (2017). Applying configurational analysis to IS behavioral research: a methodological alternative for modelling combinatorial complexities. Information Systems Journal. 27(1), 59-89.

Lu, M. T., Tzeng, G. H., Cheng, H., \& Hsu, C. C. (2015). Exploring mobile banking services for user behaviour in intention adoption: using new hybrid MADM model. Service Business, 9(3), 541-565.

Mani, Z., \& Chouk, I. (2017). Drivers of consumers' resistance to smart products. Journal of Marketing Management, 33(1-2), 76-97.

Marcoulides, G. A., Chin, W. W., \& Saunders, C. (2009). A critical look at partial least squares modelling. MIS Quarterly, 33(1), 171-175.

Mital, M., Chang, V., Choudhary, P., Papa, A., \& Pani, A. K. (2017). Adoption of Internet of Things in India: A test of competing models using a structured equation modeling approach. Technological Forecasting and Social Change. In print. https://doi.org/10.1016/j.techfore.2017.03.001

Neuhofer, B., Buhalis, D., \& Ladkin, A. (2015). Smart technologies for personalized experiences: a case study in the hospitality domain. Electronic Markets, 25(3), 243-254.

Ordanini, A., Parasuraman, A., \& Rubera, G. (2014). When the recipe is more important than the ingredients a Qualitative Comparative Analysis (QCA) of service innovation configurations," Journal of Service Research, 17(2), 134-149

Orel, F. D., \& Kara, A. (2014). Supermarket self-checkout service quality, customer satisfaction, and loyalty: Empirical evidence from an emerging market. Journal of Retailing and Consumer Services, 21(2), 118-129.

Pantano, E., \& Timmermans, H. (2014). What is Smart for Retailing? Procedia Environmental Sciences, 22, 101-107.

Pantano, E., Rese, A., \& Baier, D. (2017). Enhancing the online decision-making process by using augmented reality: A two country comparison of youth markets. Journal of Retailing and Consumer Services, 38, 81-95.

Parasuraman, A. (2000). Technology Readiness Index (TRI) a multiple-item scale to measure readiness to embrace new technologies. Journal of Service Research, 2(4), 307-320. 
Parasuraman, A., \& Colby, C. L. (2015). An updated and streamlined technology readiness index: TRI 2.0. Journal of Service Research, 18(1), 59-74.

Peng, D. X., \& Lai, F. (2012). Using partial least squares in operations management research: A practical guideline and summary of past research. Journal of Operations Management, 30(6), 467-480.

Podsakoff, P. M., MacKenzie, S. B., Lee, J. Y., \& Podsakoff, N. P. (2003). Common method biases in behavioral research: a critical review of the literature and recommended remedies. Journal of Applied Psychology, 88(5), 879

Priporas, C. V., Stylos, N., \& Fotiadis, A. K. (2017). Generation Z consumers' expectations of interactions in smart retailing: A future agenda. Computers in Human Behavior.

Purohit, D. \& Srivastava, J. (2001). Effect of manufacturer reputation, retailer reputation, and product warranty on consumer judgments of product quality: A cue diagnosticity framework. Journal of Consumer Psychology, 10(3), 123-134.

Ragin, C. (2008). Qualitative comparative analysis using fuzzy sets (fsQCA). In Configurational Comparative Methods. Qualitative Comparative Analysis (QCA) and Related techniques, Benoit Rihoux and Charles Ragin (eds). Thousand Oaks, CA: Sage Publications

Reinders, M. J., Frambach, R., \& Kleijnen, M. (2015). Mandatory use of technology-based self-service: does expertise help or hurt? European Journal of Marketing, 49(1/2), 190-211.

Renko, S., \& Druzijanic, M. (2014). Perceived usefulness of innovative technology in retailing: Consumers' and retailers' point of view. Journal of Retailing and Consumer services, 21(5), 836-843.

Research and Markets (2015), Retail IoT Market Growth and Forecast 2015 to 2020. Accessed from http://www.marketsandmarketsblog.com/retail-iot-market.html.

Rihoux, B., \& Ragin, C. C. (2009). Configurational comparative methods: Qualitative comparative analysis (QCA) and related techniques. Thousand Oaks, California: Sage.

Ringle, C. M., Wende, S., \& Becker, J. M. (2014), SmartPLS 3. Hamburg: SmartPLS.Rogers, E.M. (2003). Diffusion of innovations (5th ed.). New York: Free Press.

Rogers, E. M. (2004). A prospective and retrospective look at the diffusion model. Journal of Health Communication, 9(S1), 13-19.

Rosenbaum, M. S., \& Wong, I. A. (2015). If you install it, will they use it? Understanding why hospitality customers take "technological pauses" from self-service technology. Journal of Business Research, 68(9), 1862-1868.

Roy, S. K., Balaji, M. S., Sadeque, S., Nguyen, B., \& Melewar, T. C. (2017), Constituents and consequences of smart customer experience in retailing. Technological Forecasting and Social Change, 124, 257-270. 
Sarstedt, M., \& Ringle, C. M. (2010). Treating unobserved heterogeneity in PLS path modeling: a comparison of FIMIX-PLS with different data analysis strategies. Journal of Applied Statistics, 37(8), 1299-1318.

Scholz, M., Dorner, V., Schryen, G., \& Benlian, A. (2017). A configuration-based recommender system for supporting e-commerce decisions. European Journal of Operational Research, 259(1), 205-215.

Soper, D.S. (2014). A-priori sample size calculator for structural equation models [software]. Available from http://www.danielsoper.com/statcalc.

Stern, B. B., Royne, M. B., Stafford, T. F., \& Bienstock, C. C. (2008). Consumer acceptance of online auctions: An extension and revision of the TAM. Psychology \& Marketing, 25(7), 619-636.

Talke, K., \& Heidenreich, S. (2014). How to overcome pro-change bias: incorporating passive and active innovation resistance in innovation decision models. Journal of Product Innovation Management, 31(5), 894-907.

Tenenhaus, M., Vinzi, V. E., Chatelin, Y. M., \& Lauro, C. (2005). PLS path modelling. Computational Statistics and Data Analysis, 48(1), 159-205.

Valenzuela, S., Park, N., \& Kee, K. F. (2009). Is there social capital in a social network site? Facebook use and college students' life satisfaction, trust, and participation. Journal of Computer Mediated Communication, 14(4), 875-901.

Veloutsou, C., \& McAlonan, A. (2012). Loyalty and or disloyalty to a search engine: the case of young Millennials. Journal of Consumer Marketing, 29(2), 125-135.

Venkatesh, V., \& Bala, H. (2008). Technology acceptance model 3 and a research agenda on interventions. Decision Sciences, 39(2), 273-315.

Venkatesh, V., \& Davis, F. D. (2000). A theoretical extension of the technology acceptance model: Four longitudinal field studies. Management Science, 46(2), 186-204.

Vis, B. (2012). The comparative advantages of fsQCA and regression analysis for moderately large-N analyzes. Sociological Methods and Research, 41(1), 168-198.

Wang, W. T., \& Li, H. M. (2012). Factors influencing mobile services adoption: a brandequity perspective. Internet Research, 22(2), 142-179.

Weijters, B., Rangarajan, D., Falk, T., \& Schillewaert, N. (2007). Determinants and outcomes of customers' use of self-service technology in a retail setting. Journal of Service Research, 10(1), 3-21.

Willems, K., Smolders, A., Brengman, M., Luyten, K., \& Schöning, J. (2017). The pathto-purchase is paved with digital opportunities: An inventory of shopper-oriented retail technologies. Technological Forecasting and Social Change, 124, 228-242. 
Wu, P. L., Yeh, S. S., \& Woodside, A. G. (2014). Applying complexity theory to deepen service dominant logic: Configural analysis of customer experience-and-outcome assessments of professional services for personal transformations. Journal of Business Research, 67(8), 1647-1670.

Wünderlich, N. V., Heinonen, K., Ostrom, A. L., Patricio, L., Sousa, R., Voss, C., \& Lemmink, J. G. (2015). "Futurizing" smart service: implications for service researchers and managers. Journal of Services Marketing, 29(6/7), 442-447.

Wünderlich, N. V., Wangenheim, F. V., \& Bitner, M. J. (2013). High Tech and High Touch: A Framework for Understanding User Attitudes and Behaviours Related to Smart Interactive Services. Journal of Service Research, 16(1), 3-20. 
Figures

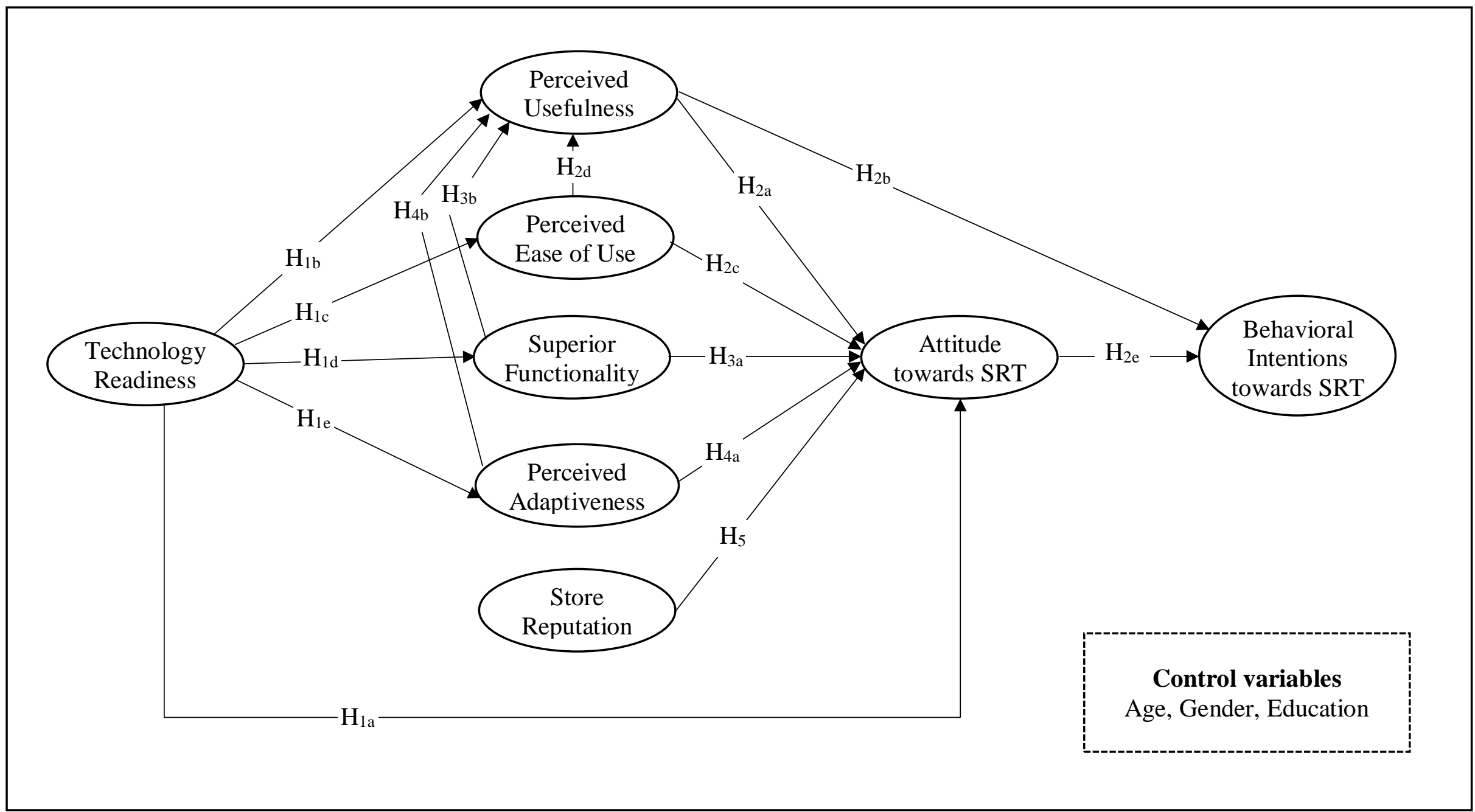

Figure 1. Research model of attitudes and behavioral intentions towards SRT 


\begin{tabular}{|c|c|c|c|c|}
\hline \multicolumn{5}{|c|}{ Table 1. Measurement model and psychometric properties of the scale } \\
\hline Constructs and measurement items & $\beta$ & $\mathrm{t}$ & $\rho$ & AVE \\
\hline \multicolumn{5}{|l|}{ Perceived usefulness (PUS) } \\
\hline PUS1 & 0.75 & 20.40 & \multirow{4}{*}{0.92} & \multirow{4}{*}{0.73} \\
\hline PUS2 & 0.91 & 55.57 & & \\
\hline PUS3 & 0.86 & 37.48 & & \\
\hline PUS4 & 0.89 & 47.05 & & \\
\hline \multicolumn{5}{|l|}{ Perceived ease of use (PEO) } \\
\hline PEO1 & 0.81 & 29.40 & \multirow{4}{*}{0.93} & \multirow{4}{*}{0.77} \\
\hline $\mathrm{PEO} 2$ & 0.91 & 54.19 & & \\
\hline PEO3 & 0.88 & 39.57 & & \\
\hline PEO4 & 0.87 & 42.44 & & \\
\hline \multicolumn{5}{|l|}{ Superior functionality (SFU) } \\
\hline SFU1 & 0.72 & 15.89 & \multirow{4}{*}{0.88} & \multirow{4}{*}{0.66} \\
\hline SFU2 & 0.83 & 32.20 & & \\
\hline SFU3 & 0.82 & 23.17 & & \\
\hline SFU4 & 0.87 & 45.10 & & \\
\hline \multicolumn{5}{|l|}{ Adaptiveness (ADP) } \\
\hline $\mathrm{ADP} 1$ & 0.89 & 45.26 & \multirow{3}{*}{0.88} & \multirow{3}{*}{0.70} \\
\hline $\mathrm{ADP} 2$ & 0.81 & 19.32 & & \\
\hline ADP3 & 0.82 & 22.48 & & \\
\hline \multicolumn{5}{|l|}{ Perceived technology readiness (PTR) } \\
\hline Optimism $(O P T)(V I F=1.20)$ & $0.51^{\circ}$ & 12.05 & \multirow{4}{*}{0.85} & \multirow{4}{*}{0.65} \\
\hline OPT1 & 0.81 & 22.04 & & \\
\hline OPT2 & 0.81 & 29.90 & & \\
\hline OPT3 & 0.80 & 18.23 & & \\
\hline Innovativeness $(I N N)(V I F=1.20)$ & $0.47^{\circ}$ & 10.74 & \multirow{4}{*}{0.85} & \multirow{4}{*}{0.65} \\
\hline INN1 & 0.83 & 24.95 & & \\
\hline INN2 & 0.87 & 53.79 & & \\
\hline INN3 & 0.71 & 14.06 & & \\
\hline Discomfort $(D I S)(V I F=1.19)$ & $0.32^{\circ}$ & 7.22 & \multirow{4}{*}{0.80} & \multirow{4}{*}{0.57} \\
\hline DIS1 & 0.75 & 7.07 & & \\
\hline DIS2 & 0.82 & 9.81 & & \\
\hline DIS3 & 0.69 & 7.43 & & \\
\hline Insecurity $(I N S)(V I F=1.19)$ & $0.34^{\circ}$ & 5.33 & \multirow{4}{*}{0.83} & \\
\hline INS1 & 0.63 & 5.31 & & 062 \\
\hline INS2 & 0.86 & 11.61 & & 0.02 \\
\hline INS3 & 0.85 & 11.20 & & \\
\hline Store Reputation (REP) & & & & \\
\hline REP1 & 0.87 & 30.16 & & \\
\hline REP2 & 0.90 & 36.98 & 0.90 & 0.76 \\
\hline REP3 & 0.84 & 23.17 & & \\
\hline Attitude towards SRT (ATT) & & & & \\
\hline ATT1 & 0.94 & 91.32 & & \\
\hline ATT2 & 0.95 & 106.69 & 0.96 & 0.89 \\
\hline ATT3 & 0.94 & 95.45 & & \\
\hline Behavioral intentions towards SRT & & & & \\
\hline BIN1 & 0.75 & 20.12 & & \\
\hline BIN2 & 0.88 & 46.77 & & \\
\hline BIN3 & 0.91 & 43.19 & 0.92 & 0.12 \\
\hline BIN4 & 0.92 & 55.96 & & \\
\hline
\end{tabular}


$\beta$ - Standardized factor loadings; $\mathrm{t}$ - t-statistic; $\rho$ - Composite reliability; AVE - Average variance extracted; ${ }^{\circ}$ - second-order factor loadings. 
Table 2. Descriptive statistics and correlations

\begin{tabular}{cccccccccccc}
\hline & OPT & INN & DIS & INS & PEO & PUS & SFU & ADP & REP & ATT & BIN \\
OPT & 0.81 & & & & & & & & & & \\
INN & 0.40 & 0.81 & & & & & & & & & \\
DIS & 0.07 & 0.13 & 0.76 & & & & & & & & \\
INS & 0.12 & 0.06 & 0.38 & 0.79 & & & & & & & \\
PEO & 0.36 & 0.24 & 0.08 & 0.15 & 0.88 & & & & & & \\
PUS & 0.39 & 0.26 & -0.06 & 0.06 & 0.65 & 0.86 & & & & & \\
SFU & 0.20 & 0.25 & 0.05 & 0.06 & 0.41 & 0.50 & 0.81 & & & & \\
ADP & 0.12 & 0.16 & 0.00 & 0.04 & 0.22 & 0.38 & 0.55 & 0.84 & & & \\
REP & 0.18 & 0.22 & 0.04 & 0.05 & 0.22 & 0.27 & 0.31 & 0.32 & 0.87 & & \\
ATT & 0.28 & 0.15 & -0.03 & 0.04 & 0.51 & 0.59 & 0.43 & 0.41 & 0.31 & 0.95 & \\
BIN & 0.27 & 0.25 & 0.08 & 0.12 & 0.37 & 0.51 & 0.60 & 0.52 & 0.39 & 0.51 & 0.87 \\
& & & & & & & & & & & \\
Mean & 5.63 & 4.67 & 4.12 & 3.91 & 5.48 & 5.21 & 5.10 & 4.89 & 5.17 & 5.30 & 5.25 \\
S.D. & 0.84 & 11.03 & 1.08 & 1.27 & 0.99 & 1.30 & 1.02 & 0.93 & 0.93 & 1.11 & 1.04 \\
\hline
\end{tabular}

Square root AVE is in italics on the diagonal. Correlations are below diagonal. S.D. Standard Deviation 
Table 3. Structural model results

\begin{tabular}{cccc}
\hline \multicolumn{1}{c}{ Paths Specified } & Standardized Coefficient & t-value & p value \\
\hline Control relationships & & & \\
Gender $\rightarrow$ ATT & 0.04 & 0.83 & 0.41 \\
Gender $\rightarrow$ BIN & 0.04 & 0.76 & 0.45 \\
Age $\rightarrow$ ATT & 0.01 & 0.08 & 0.93 \\
Age $\rightarrow$ BIN & 0.08 & 1.26 & 0.21 \\
Education $\rightarrow$ ATT & 0.05 & 0.72 & 0.47 \\
Education $\rightarrow$ BIN & -0.03 & 0.43 & 0.67 \\
Model relationships & & & \\
$\mathrm{H}_{1 \mathrm{a}}:$ PTR $\rightarrow$ ATT & -0.04 & 0.71 & 0.48 \\
$\mathrm{H}_{1 \mathrm{~b}}:$ PTR $\rightarrow$ PUS & 0.07 & 1.30 & 0.19 \\
$\mathrm{H}_{1 \mathrm{c}}:$ PTR $\rightarrow$ PEO & 0.37 & 6.41 & $<0.01$ \\
$\mathrm{H}_{1 \mathrm{~d}}:$ PTR $\rightarrow$ SFU & 0.26 & 3.50 & $<0.01$ \\
$\mathrm{H}_{1 \mathrm{e}}:$ PTR $\rightarrow$ ADP & 0.16 & 1.95 & $<0.05$ \\
$\mathrm{H}_{2 \mathrm{a}}:$ PUS $\rightarrow$ ATT & 0.34 & 4.85 & $<0.01$ \\
$\mathrm{H}_{2 \mathrm{~b}}:$ PUS $\rightarrow$ BIN & 0.30 & 4.25 & $<0.01$ \\
$\mathrm{H}_{2 \mathrm{c}}:$ PEO $\rightarrow$ ATT & 0.21 & 2.59 & $<0.01$ \\
$\mathrm{H}_{2 \mathrm{~d}}:$ PEO $\rightarrow$ PUS & 0.52 & 7.51 & $<0.01$ \\
$\mathrm{H}_{2 \mathrm{e}}:$ ATT $\rightarrow$ BIN & 0.27 & 3.64 & $<0.01$ \\
$\mathrm{H}_{3 \mathrm{a}}: \mathrm{SFU} \rightarrow$ ATT & 0.02 & 0.24 & 0.81 \\
$\mathrm{H}_{3 \mathrm{~b}}: \mathrm{SFU} \rightarrow$ PUS & 0.19 & 2.47 & $<0.05$ \\
$\mathrm{H}_{4 \mathrm{a}}:$ ADP $\rightarrow$ ATT & 0.15 & 2.57 & $<0.01$ \\
$\mathrm{H}_{4 \mathrm{~b}}:$ ADP $\rightarrow$ PUS & 0.16 & 2.59 & $<0.01$ \\
$\mathrm{H}_{5}:$ REP $\rightarrow$ ATT & 0.12 & 2.07 & $<0.05$ \\
\hline
\end{tabular}




\begin{tabular}{|c|c|c|c|c|c|c|c|}
\hline \multirow{2}{*}{ Antecedents } & \multicolumn{3}{|c|}{$\begin{array}{c}\text { Presence of Attitude } \\
\text { towards SRT } \\
\text { Solutions }\end{array}$} & \multicolumn{4}{|c|}{$\begin{array}{c}\text { Absence of Attitude towards } \\
\text { SRT } \\
\text { Solutions } \\
\end{array}$} \\
\hline & 1 & 2 & 3 & 1 & 2 & 3 & 4 \\
\hline Technology readiness (PTR) & & & & & & $\bigotimes$ & \\
\hline Perceived usefulness (PUS) & & & & $\bigotimes$ & $\bigotimes$ & $\bigotimes$ & $\bigotimes$ \\
\hline Perceived ease of use (PEO) & 0 & $\bullet$ & 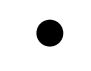 & & ○ & & $\bigotimes$ \\
\hline Superior functionality (SFU) & & & & $\bigotimes$ & $\bigotimes$ & $\otimes$ & $\bigotimes$ \\
\hline Perceived adaptiveness (ADP) & & & & $\otimes$ & $\otimes$ & $\otimes$ & \\
\hline Store reputation (REP) & 0 & 9 & 0 & 0 & & & 0 \\
\hline Consistency & 0.97 & 0.97 & 0.97 & 0.84 & 0.83 & 0.84 & 0.85 \\
\hline Raw coverage & 0.72 & 0.66 & 0.67 & 0.49 & 0.48 & 0.45 & 0.42 \\
\hline Unique coverage & 0.08 & 0.02 & 0.03 & 0.003 & 0.00 & 0.00 & 0.007 \\
\hline Overall solution consistency & & 0.97 & & & & & \\
\hline Overall solution coverage & & 0.77 & & & & & \\
\hline
\end{tabular}

Note: $\bigcirc=$ Core causal condition present, $\bigotimes=$ Core causal condition absent

$\bullet$ = Contributing causal condition present, $\otimes=$ Contributing causal condition absent. 
Table 5. Configurations for Behavioral intentions towards SRT

\begin{tabular}{|c|c|c|c|c|c|c|c|c|c|}
\hline \multirow{3}{*}{ Antecedents } & \multicolumn{5}{|c|}{$\begin{array}{l}\text { Presence of behavioral } \\
\text { intentions for SRT }\end{array}$} & \multicolumn{4}{|c|}{$\begin{array}{l}\text { Absence of behavioral } \\
\text { intentions for SRT }\end{array}$} \\
\hline & \multicolumn{5}{|c|}{ Solutions } & \multicolumn{4}{|c|}{ Solutions } \\
\hline & 1 & 2 & 3 & 4 & 1 & 2 & 3 & 4 & 5 \\
\hline Attitude (ATT) & & & & & & & $\otimes$ & & \\
\hline Technology readiness (PTR) & ○ & & ○ & ○ & & & & $\bigotimes$ & $\bigotimes$ \\
\hline Perceived usefulness (PUS) & $\otimes$ & $\bullet$ & $\bullet$ & ○ & & & & & \\
\hline Perceived ease of use (PEO) & & 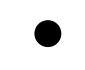 & $\bullet$ & ○ & & & $\bigotimes$ & $\bigotimes$ & \\
\hline Superior functionality (SFU) & ○ & ○ & & $\bullet$ & & $\bigotimes$ & & & $\bigotimes$ \\
\hline adaptiveness & O & 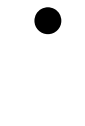 & 0 & & $\otimes$ & & & & $\bigotimes$ \\
\hline Store reputation (REP) & ○ & 0 & ○ & ص & $\bigotimes$ & $\bigotimes$ & & & \\
\hline Consistency & 0.98 & 0.98 & 0.98 & 0.98 & 0.73 & 0.80 & 0.75 & 0.71 & 0.81 \\
\hline Raw coverage & 0.19 & 0.70 & 0.65 & 0.66 & 0.53 & 0.52 & 0.42 & 0.47 & 0.57 \\
\hline Unique coverage & 0.01 & 0.07 & 0.02 & 0.03 & 0.03 & 0.02 & 0.01 & 0.01 & 0.06 \\
\hline Overall solution consistency & & & & & & & 0.62 & & \\
\hline Overall solution coverage & & & & & & & 0.74 & & \\
\hline
\end{tabular}

Note: $\bigcirc=$ Core causal condition present, $\bigotimes=$ Core causal condition absent

$\bullet=$ Contributing causal condition present, $\otimes=$ Contributing causal condition absent. 